\title{
CARTOGRAFIA DA MIGRAÇÃO INTERNA EM MOÇAMBIQUE ENTRE 1997 E 2007
}

\author{
Cartography of internal migration in Mozambique \\ between 1997 and 2007
}

\author{
Ramos Cardoso Muanamoha* \\ Inês Macamo Raimundo*
}

\begin{abstract}
Resumo. O texto "Cartografia da migração interna em Moçambique entre 1997 e 2007" resulta de uma análise exploratória da informação referente à migração interna das bases de dados dos censos demográficos de 1997 e 2007, respectivamente o segundo e o terceiro de Moçambique, após a independência nacional em 1975. A análise é feita em torno da migração de toda a vida ou acumulada, observada entre as províncias, em 1997 e 2007, e também da migração registada no quinquénio anterior ao censo demográfico de 2007 (isto é, o quinquénio 2002-2007). Como resultados da análise, o texto apresenta fluxos migratórios entre as províncias e, também, os volumes da migração acumulada por sexo e província, em 1997 e 2007, bem como volumes da migração interprovincial do quinquénio 2002-2007. Ainda, a análise permitiu agrupar as províncias em três categorias, de acordo com as suas tendências migratórias: a primeira, composta por províncias de imigração (Niassa, Manica e Maputo); a segunda, por províncias de emigração (Zambézia, Tete, Inhambane e Gaza); e a terceira, por províncias que, de um período para outro, mudaram de uma tendência migratória para outra (Sofala, Cabo Delgado, Nampula e Cidade de Maputo). Por último, os resultados indicam que, nas províncias do Sul de Moçambique, a proporção de mulheres no volume total de migrantes supera à dos homens.
\end{abstract}

Palavras-chave: Moçambique; província; migração interna; migração acumulada.

\begin{abstract}
The paper "Cartography of internal migration in Mozambique between 1997 and 2007" results from an exploratory analysis of information pertaining to internal migration based on demographic census data between 1997 and 2007 respectively; the second and third censuses of Mozambique following national independence in 1975. The analysis is made according to the lifelong or accumulated migration observed among
\end{abstract}

Universidade Eduardo Mondlane, Faculdade de Letras e Ciências Sociais, Departamento de Geografia. Maputo, Moçambique. 


\begin{abstract}
Mozambique's eleven provinces in the censuses of 1997 and 2007. Also registered is migration in the five-year period before the demographic census of 2007 (that is, the period between 2002 and 2007). As a result of this analysis, the paper presents migration flows among provinces and also the volume of accumulated migration by sex and province, in 1997 and 2007. These data are presented as the volumes of inter-provincial migration of five-year 2002-2007. Furthermore, the analysis permits the grouping of the provinces in three categories according migratory trends: the first is composed of immigration provinces (Niassa, Manica and Maputo); the second of emigration provinces (Zambezia, Tete, Inhambane and Gaza); and the third, of provinces which from one period to another, changed the migration trend (Sofala, Cabo Delgado, Nampula and the City of Maputo). Lastly, the results indicate that in southern provinces of Mozambique, the proportion of women in total volume of migrants surpasses the proportion of men.
\end{abstract}

Keywords: Mozambique; province; internal migration; accumulated migration.

\title{
Introdução
}

Nos últimos tempos, estudos sobre migrações internas em Moçambique têm estado a aumentar significativamente, se considerarmos o número de trabalhos de fim dos cursos de licenciatura, dissertações de Mestrado ou teses de Doutoramento na área de ciências humanas. Cada um destes estudos tem contribuído para a compreensão do fenómeno migratório em Moçambique e da sua geografia, em particular no que se refere às origens e aos destinos dos migrantes internos.

O Instituto Nacional de Estatística (INE) de Moçambique tem colectado, de dez em dez anos, informação sobre migrações internas, através dos censos demográficos. Note-se que o primeiro censo demográfico de Moçambique independente, o de 1980, foi liderado pela então Direcção Nacional de Estatísticas. Depois do primeiro, seguiram-se mais três censos demográficos, sendo o último o de 2017, cujos resultados definitivos não foram ainda publicados. O INE assume a liderança a partir do censo demográfico de 1997, o segundo após a independência nacional, que passou a incluir quatro questões sobre migrações, entretanto, consideradas por muitos estudiosos como insuficientes para uma compreensão mais exaustiva do fenómeno migratório em Moçambique. As 4 questões sobre migrações, que são incluídas nos censos demográficos, desde o de 1997, têm a ver com a seguinte informação: (i) lugar de residência actual; (ii) lugar de nascimento; (iii) lugar de residência 1 ano anterior à data do censo; (iv) lugar de residência 5 anos anteriores à data do censo.

Raimundo e Muanamoha (2013) observam que as questões sobre migrações, que actualmente são incluídas nos censos demográficos de 
Moçambique, permitem aferir apenas informação sobre estoques de migração dos lugares e períodos considerados e não sobre quem migra e nem como é tomada a decisão para migrar, entre outros aspectos.

Assim, baseado na informação resultante das 4 perguntas sobre migração dos censos demográficos de 1997 e 2007, em Moçambique, o presente artigo apresenta, por província, volumes e taxas de migração de toda a vida ou acumulada em 1997 e 2007, e da migração do quinquénio anterior à data do censo de 2007 (portanto, 2002-2007). Os resultados, que são apresentados em mapas, visualizam a dinâmica migratória interna em Moçambique, entre 1997 e 2007.

Note-se, porém, que o intervalo temporal que separa o censo demográfico de 1997 (o segundo de Moçambique independente) do de 1980 (o primeiro) é de 17 anos. Isto deveu-se à instabilidade político-militar vivida no País, que não permitiu a realização da operação censitária em 1990. Em 1997, quando se realizou o II Recenseamento Geral da População e Habitação, o País estava ainda em fase de reconstrução pós-guerra, pois o Acordo Geral de Paz, assinado entre o Governo de Moçambique e o Movimento de Resistência Moçambicana e o subsequente processo de retorno de moçambicanos que viviam como refugiados no estrangeiro, tinham transcorrido apenas 5 anos. Por isso, o censo demográfico de 1997 reveste-se de particular importância no que respeita à informação sobre migração nele colectada.

Este texto foi elaborado com base na informação sobre migração interprovincial dos censos demográficos de 1997 e 2007, com enfoque para a migração acumulada ou de toda a vida em 1997 e 2007, bem como a migração do quinquénio anterior à data do censo de 2007 (isto é, 2002-2007).

\section{Classificação administrativa de Moçambique}

Para uma melhor compreensão da dinâmica da migração interna em Moçambique, é importante que se conheça, primeiro, a divisão administrativa moçambicana. A República de Moçambique é, desde 1975, um território que, administrativamente, se reparte em províncias, distritos, postos administrativos, localidades, cidades, distritos urbanos, bairros, quarteirões e zonas. As províncias constituem as unidades político-administrativas de nível superior, sendo elas (e as respectivas capitais), do norte ao sul, as seguintes: Cabo Delgado (Pemba), Niassa (Lichinga), Nampula (Nampula), Zambézia (Quelimane), Tete (Tete), Manica (Chimoio), Sofala (Beira), Inhambane (Inhambane), Gaza (Xai-Xai), Maputo (Matola) e Cidade de Maputo, a capital do País (Mapa 1). 


\section{Mapa 1: Mapa das cidades de Moçambique}

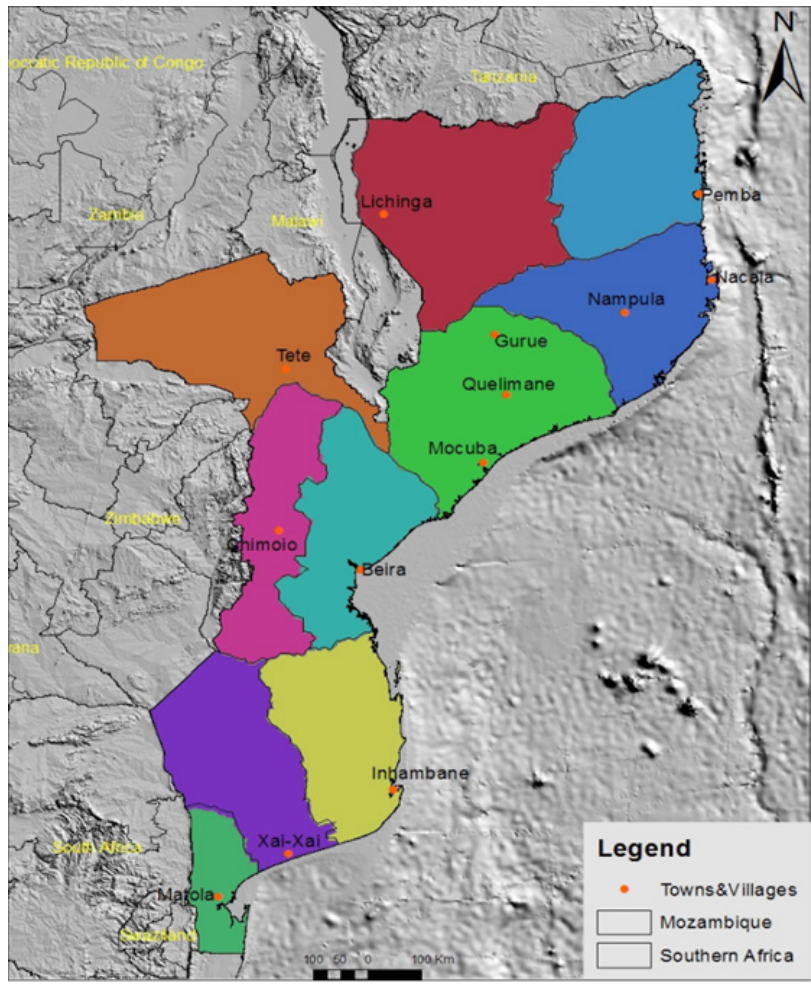

Fonte: Mapa desenhado por Luciano Langa com base na base de dados Cartográfica do GeoLab da Faculdade de Letras e Ciências Sociais da Universidade Eduardo Mondlane.

Historicamente, a primeira divisão administrativa de Moçambique independente aconteceu em 1975, quando os antigos distritos foram elevados à categoria de províncias e as antigas circunscrições à de distritos (Pililão 1989). A segunda divisão ocorreu em 1986. Esta segunda obedeceu os seguintes critérios: i) densidade populacional; ii) desenvolvimento económico e social, incluindo a existência de infraestruturas sociais (escolas primárias com 2 ciclos de ensino; escolas secundárias e técnico-profissionais; postos e centros de saúde; hospitais rurais, provinciais e centrais; etc.); iii) importância política e história do lugar; e iv) extensão rural. Ainda, a separação da cidade de Maputo da de Matola e a elevação da primeira à categoria de província tornaram-se marcos mais visíveis desta segunda divisão administrativa. Deste modo, a nova divisão administrativa passou a apresentar o seguinte cenário:

1. Os distritos passaram a ser classificados por categorias, nomeadamente, distritos de $1^{\mathrm{a}}, 2^{\mathrm{a}}$ e $3^{\mathrm{a}}$ classe. Em 2007, havia um total de 150 distritos; 
2. As cidades, à semelhança dos distritos, passaram a ser classificadas nas seguintes categorias: cidades de categoria $A$ (aquelas com mais de 1 milhão de habitantes), B (entre 500 mil e 1 milhão de habitantes), C (entre 100 mil e 500 mil habitantes) e D (entre 20 mil e 100 mil habitantes). Na categoria A encontra-se a Cidade de Maputo;

3. Introdução da unidade administrativa designada por "Posto Administrativo", que passou a subordinar-se ao distrito rural;

4. A Cidade de Maputo passou a dividir-se, administrativamente, em Distritos Urbanos.

Portanto, para efeitos deste trabalho, a informação baseia-se na divisão administrativa efectiva entre 1975 e 2007, que inclui ainda conceitos de "mega cidade", em referência à cidade com mais de 1 milhão de habitantes, como é o caso da cidade de Maputo; "cidade grande", aplicável às cidades da Beira, Nampula e Quelimane; "cidades médias", que incluem cidades da classe C e as restantes capitais provinciais e outras cidades com igual efectivo populacional; e "cidades pequenas", as da categoria D que, geralmente, são as capitias dos distritos.

\section{Movimentos migratórios e deslocamentos populacionais em Moçambique: um direito constitucional}

Quando se trata de migrações, o mundo contemporâneo apega-se mais ao fenómeno que acontece fora dos limites territoriais dos Estados. No caso de Moçambique, pouca atenção é dada ao que acontece internamente, não obstante as permanentes deslocações em decorrência da instabilidade política registada até 5 anos antes do segundo censo demográfico, o de 1997, e os fenómenos subsequentes que caracterizaram a história política, económica e ambiental de Moçambique, até 2007. Raimundo e Raimundo (2017) destacam as transformações em Moçambique, com impacto na migração interna, pois, segundo eles, o discurso das "descobertas de recursos minerais" e os investimentos decorrentes da valorização destes recursos vieram mudar a geografia de Moçambique, em termos de assentamentos populacionais e do sentido das migrações.

As deslocações populacionais têm desempenhado um papel vital na transformação estrutural das economias ao longo da história, sendo por isso impensável que haja sociedades cujas populações não migram. As migrações podem ocorrer dentro dos limites do território, tratando-se, deste modo, de migrações internas.

As migrações internas consideradas neste texto são aquelas registadas nos censos demográficos de 1997 e 2007, dentro do território da República de Moçambique, e que ocorreram entre as províncias. Como migrante interno considera-se todo indivíduo não-nativo da província de residência na data do 
censo, cuja província de residência anterior fosse diferente da actual. O termo migrante é utilizado no sentido de generalizar tanto a condição de imigrante (o indivíduo que entrou) como a de emigrante (o indivíduo que saiu da província de enumeração), dependendo do referencial que se adopte.

Importa referir que, na República de Moçambique, não existem, desde 1990, restrições de deslocações populacionais, pese embora as deslocações populacionais fossem condicionadas, até então, pela guerra e algumas restrições decorrentes de exigências de guias de marcha (Raimundo, 2009). As deslocações populacionais, incluindo migração (mudança habitual do local de residência) são um direito constitucional, expresso no Artigo 55 sobre liberdade de residência e de circulação (República de Moçambique, 2004)'. Portanto, a análise que é feita neste estudo diz respeito aos movimentos internos assegurados pela Constituição da República de Moçambique.

\section{A cartografia da migração interna em Moçambique entre 1997 e 2007}

\subsection{Fluxos migratórios entre províncias}

A cartografia da migração interna em Moçambique (entre 1997 e 2007), aqui apresentada, constitui seguimento de uma publicação anterior de Raimundo e Muanamoha (2013), na qual os autores estimaram volumes e taxas de imigração e emigração para cada uma das províncias moçambicanas, nos períodos 2002-2007 e 2006-2007, bem como o resultado líquido dos intercâmbios havidos entre as diferentes províncias. Nesta cartografia, pretende-se dar mais ênfase aos fluxos migratórios interprovinciais e aferir as causas associadas a eles.

\section{Cidade de Maputo}

A Cidade de Maputo, capital da República de Moçambique, com uma área de 310 km², possuía uma população de 966.837 e 1.094 .628 habitantes, em 1997 e 2007, respectivamente. Sem negligenciar o papel da fecundidade sobre o crescimento da população, pode-se acreditar que, por tratar-se da cidade capital que concentra o poder político e administrativo, a migração tem contribuído significativamente para o crescimento da população. Os Mapas 2 e 3 mostram que em 1997 e 2017, os imigrantes de toda a vida da Cidade de Maputo eram maioritariamente das províncias de Gaza (36\% dos imigrantes), Inhambane (29,3\%), Maputo província (20\%) e Zambézia (5,7\%). Este cenário não mudou, em 2007, em que os imigrantes continuavam a ser

\footnotetext{
Ponto 1: "Todos os cidadãos têm o direito de fixar residência em qualquer parte do território nacional". Ponto 2: "Todos os cidadãos são livres de circular no interior e para exterior do território nacional, excepto os judicialmente privados desse direito".
} 
maioritariamente de Gaza (34,1\%), Inhambane (29,1\%), província de Maputo $(15,6 \%)$ e Zambézia (8,8\%). Entretanto, em 2007, observa-se uma ligeira redução de imigrantes de Gaza e um relativo incremento dos imigrantes da província da Zambézia.

O predomínio de migrantes das províncias de Maputo, Gaza e de Inhambane (todas do Sul de Moçambique) pode ser explicado pela proximidade geográfica e, ainda, como seguimento da migração laboral para África do Sul. Historicamente, estas três províncias foram sempre as principais fornecedoras de mão-de-obra para a África do Sul (Covane, 1996; Penvenne, 1982; De Vletter, 2000; Raimundo, 2010; Muanamoha, 2010). Em relação à província da Zambézia, o estudo de Saide e Pitrosse (2012) mostra que população desta província iniciou, também, a rota migratória para as plantações da província Sul-africana de Mpumalanga. Por isso, a Cidade de Maputo é usada como porto de trânsito para a África do Sul. Entretanto, Sitói (2000) observa que o aumento de imigrantes da Zambézia na Cidade de Maputo é motivado pela necessidade de sobrevivência destes imigrantes que são encontrados maioritariamente nos mercados informais, ou noutras ocupações como guardas de prédios, limpadores de carros, entre outras actividades.

\section{Mapa 2: Fluxos migratórios internos de toda a vida - Cidade de Maputo, 1997}

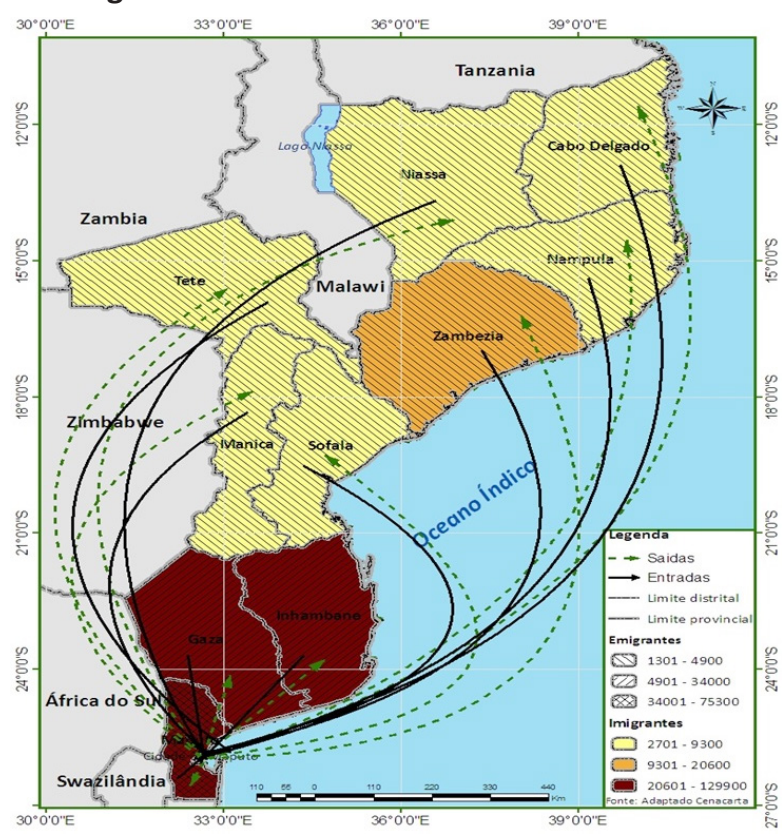

Fonte: INE (1999) 


\section{Mapa 3: Fluxos migratórios internos de toda a vida - Cidade de Maputo, 2007}

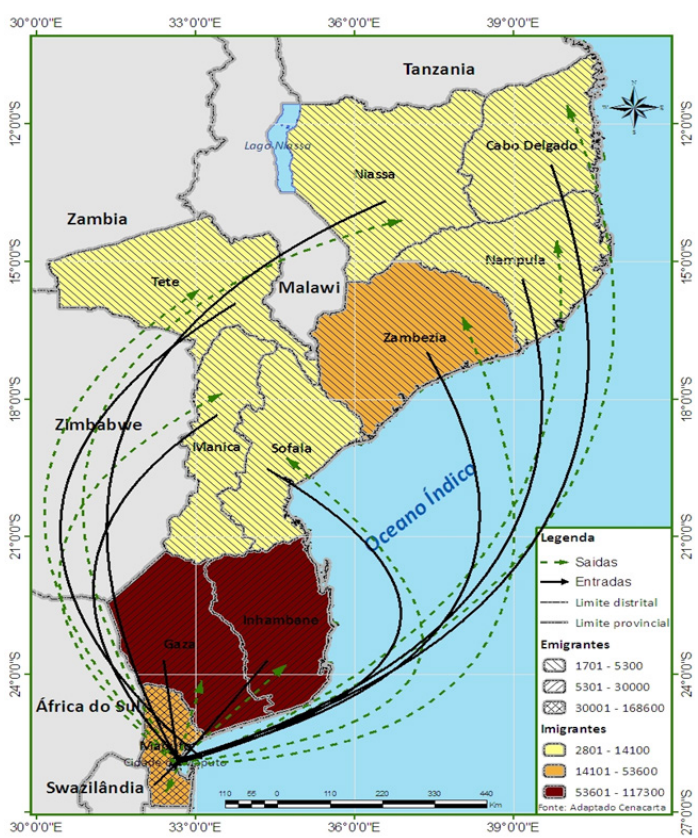

Fonte: INE (2010)

\section{Província de Maputo}

A província de Maputo, localizada no sul de Moçambique, possui uma área de $22.693 \mathrm{Km}^{2}$ e uma população de 806.179 e 1.205.709 habitantes em 1997 e 2007, respectivamente. A sua proximidade geográfica da República da África do Sul e do Reino da Suazilândia, bem como da Cidade de Maputo, pode ter influência na tendência da migração nesta província. Obviamente, duas correntes migratórias podem ser observadas nela: uma corrente em direcção à Cidade de Maputo, tendo como motivações as mesmas das outras províncias do Sul; e outra corrente em direcção à África do Sul e Suazilândia. Esta segunda corrente é explicada pela histórica migração laboral para as plantações da cana-de-açúcar na Swazilândia e África do Sul, assim como para as minas da África do Sul. Por outro lado, pode-se admitir que os mais de 2 séculos de migração para estes países, podem ter criado, obviamente, uma dispersão geográfica das famílias e, por isso, a necessidade de reunificação justifique, em parte, as correntes migratórias actuais.

O Mapa 4, dos fluxos migratórios da província de Maputo, indica que a maioria dos imigrantes de toda a vida, desta província, em 1997, era das províncias de Gaza (33,2\% dos imigrantes), Inhambane (29,8\%) e Cidade de Maputo (28,5\%). Já em 2007, a maior imigração acumulada na província de Maputo provinha da Cidade de Maputo (com 37,2\% dos imigrantes), seguida 
de Inhambane (26,8\%), Gaza (25\%) e Zambézia (4,7\%). Como foi explicado anteriormente, a província de Maputo ocupa simultaneamente a posição de emissora de migrantes para Swazilândia e África do Sul, assim como para a Cidade de Maputo, e a de receptora de migrantes, conforme ilustra o Mapa 5. Mais uma vez, no conjunto das províncias das regiões centro e norte de Moçambique, a província da Zambézia se destaca na imigração da província de Maputo.

Mapa 4: Fluxos migratórios internos de toda a vida - província de Maputo, 1997

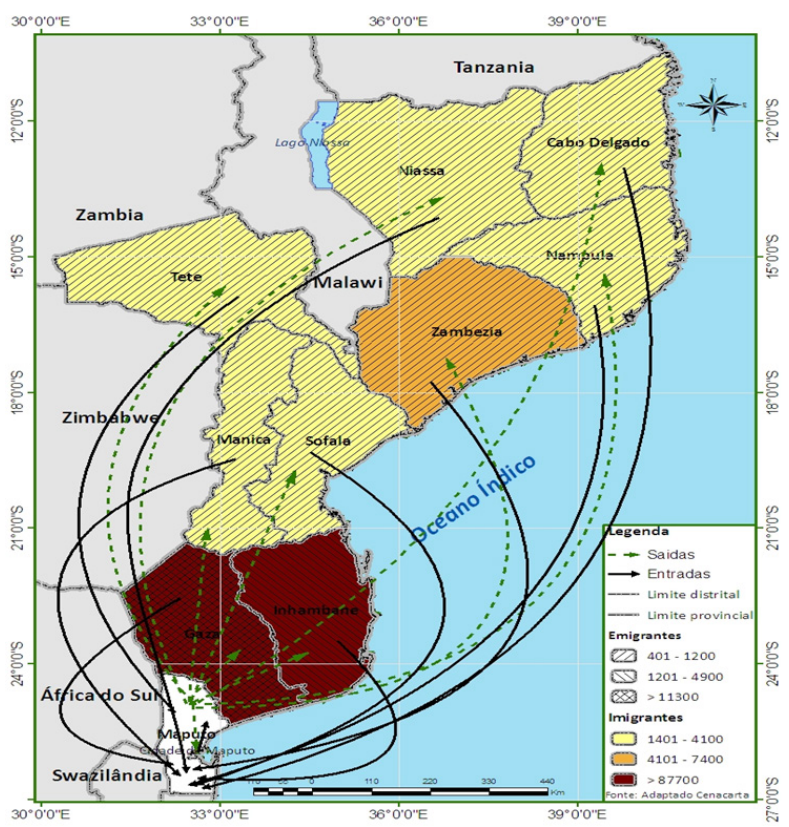

Fonte: INE (1999) 


\section{Mapa 5: Fluxos migratórios internos de toda a vida - província de Maputo, 2007}

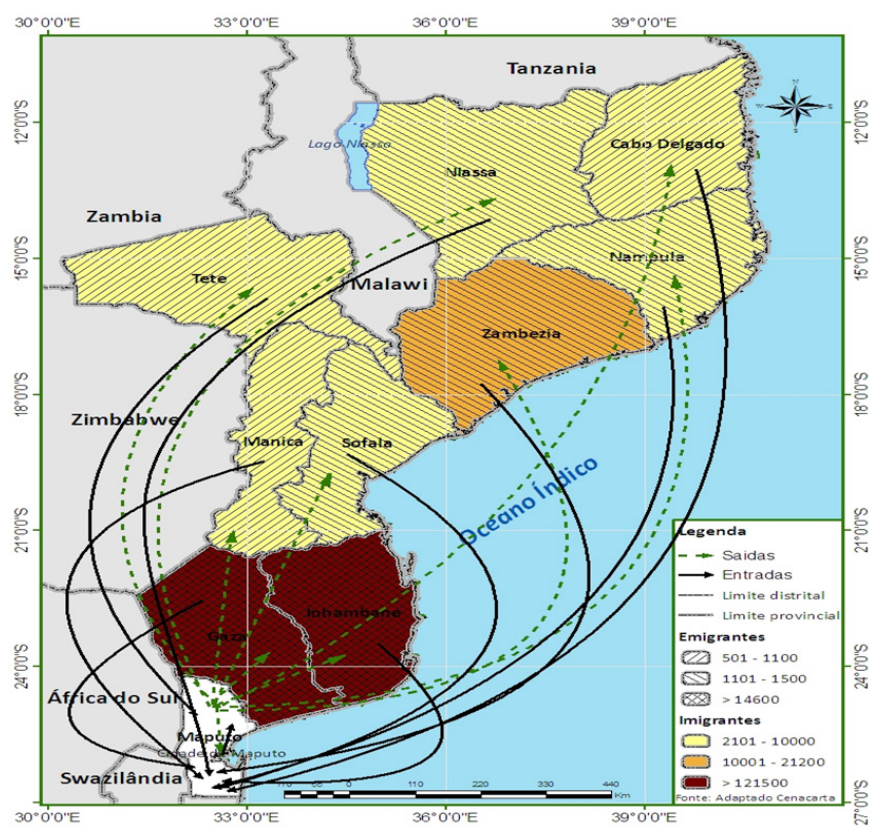

Fonte: INE (2010)

\section{Província de Gaza}

Com uma área de $75.334 \mathrm{~km}^{2}$, a província de Gaza situa-se no sul de Moçambique e, administrativamente, é composta por 14 distritos ${ }^{2}$. A sua população perfazia 1.062.380 e 1.228.514 habitantes, em 1997 e 2007, respectivamente. À semelhança da província de Maputo, Gaza faz fronteiras com as Repúblicas da África do Sul e do Zimbabwe. Esta província tem uma longa história de trabalho migratório para a actual Cidade de Maputo (Penvenne, 1982) e para a África do Sul.

O Mapa 6 mostra que os emigrantes acumulados de Gaza, em 1997, residiam, maioritariamente, na Cidade Maputo (54,2\% dos emigrantes) e nas províncias de Maputo (36,6\%) e Inhambane (5,9\%). Igualmente, em 2007, a maioria dos emigrantes acumulados de Gaza (mapa 7) residia na Cidade de Maputo (46,6\% dos emigrantes) e nas províncias de Maputo $(45,1 \%)$ e Inhambane (5,3\%). Portanto, em 2007, a proporção de emigrantes de Gaza que se dirigiram à província de Maputo incrementou, em detrimento da Cidade de Maputo e, ligeiramente, da província de Inhambane.

\footnotetext{
A divisão administrativa da província de Gaza foi redefinida em 2016. Assim, os antigos Postos Administrativos de Mapai (que pertencia ao Distrito de Chiculacuala), Limpopo (do antigo Distrito de Bilene) e Chongone (que fazia parte do Distrito de Xai-Xai) foram elevados à categoria de Distritos (Assembleia da República: Lei n.o 3/2016).
} 
Mapa 6: Fluxos migratórios internos de toda a vida - Gaza, 1997

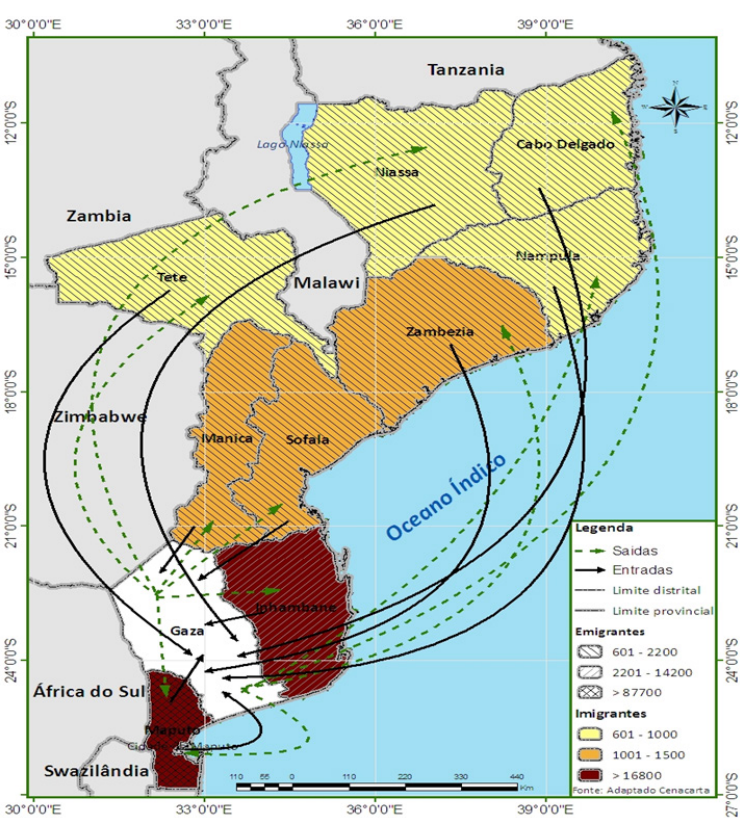

Fonte: INE (1999)

Mapa 7: Fluxos migratórios internos de toda a vida - Gaza, 2007

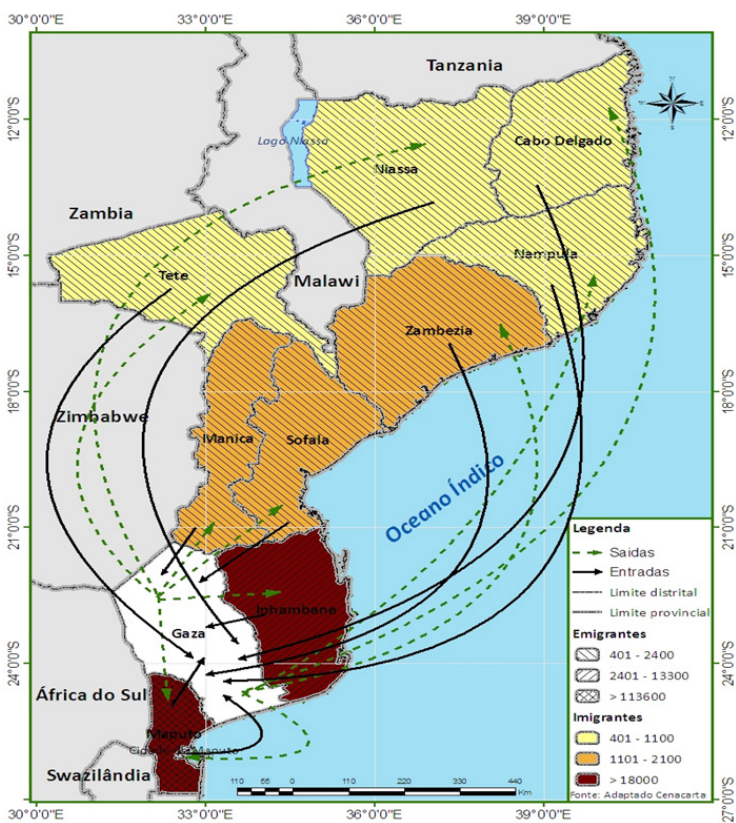

Fonte: INE (1999) 


\section{Província de Inhambane}

A província de Inhambane, também localizada no sul de Moçambique, contrariamente às duas anteriores, não tem fronteiras internacionais. Esta província delimita o espaço geográfico na região sul de Moçambique de envio de mão-de-obra para a África do Sul. Ela possui uma superfície de 68.775 $\mathrm{km}^{2}$ e a sua população, em 1997 e 2007, totalizava 1.123 .079 e 1.271 .818 habitantes, respectivamente. O Mapa 8 indica que a maioria dos emigrantes acumulados da província de Inhambane residia, em 1997, na Cidade de Maputo (43,6\% dos emigrantes) e nas províncias de Maputo (32,4\%), Sofala $(11,8 \%)$ e Gaza (7\%). Entretanto, em 2007 (Mapa 9), a província de Maputo esteve em primeiro lugar, na recepção de emigrantes de Inhambane (com $44,5 \%$ dos emigrantes), seguida pela Cidade de Maputo (36,7\%) e províncias de Sofala $(7,7 \%)$ e Gaza $(6,6 \%)$.

\section{Mapa 8: Fluxos migratórios internos de toda a vida - Inhambane, 1997}

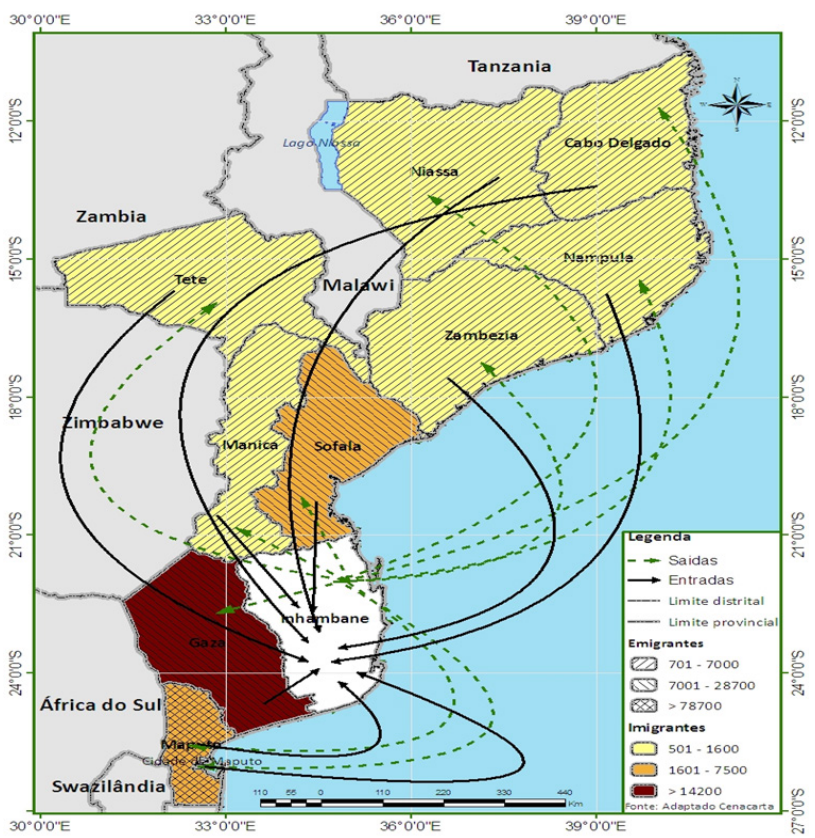

Fonte: INE (1999) 


\section{Mapa 9: Fluxos migratórios internos de toda a vida - Inhambane, 2007}

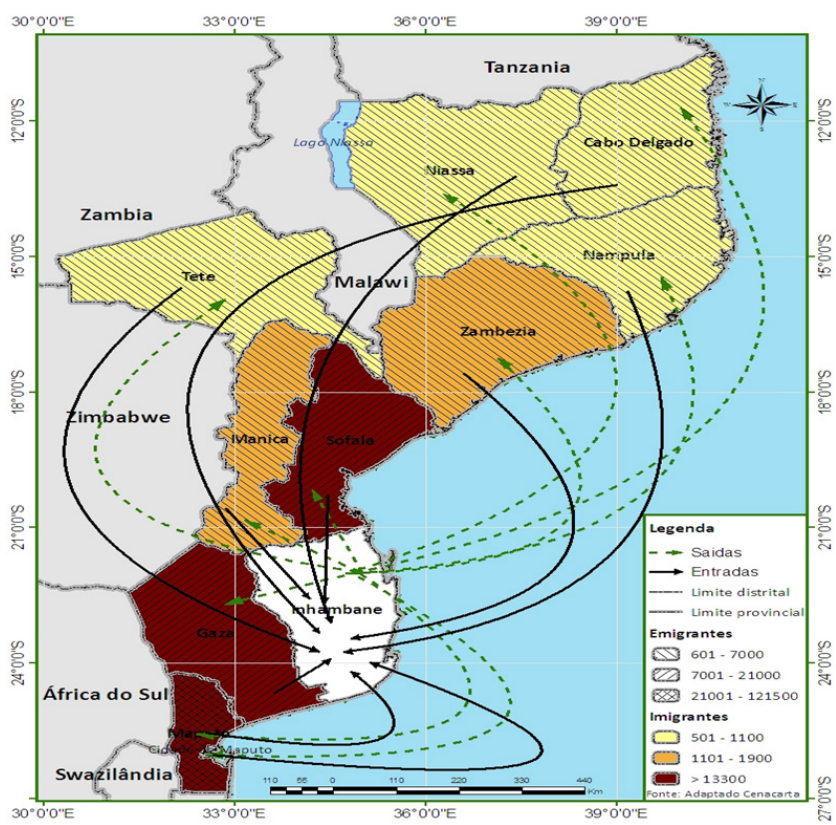

Fonte: INE (2010)

\section{Província de Sofala}

A província de Sofala, cuja capital é a cidade da Beira, localiza-se na região centro de Moçambique e possui um território com uma área de 67.753 km² (MINED, 1986). Em 1997, Sofala tinha uma população de 1.289.390 habitantes, tendo passado para 1.642.920 habitantes em 2007. A sua capital, cidade da Beira (da categoria B), é muito atractiva aos imigrantes. Na sua maioria, os imigrantes nesta província, em 1997 e 2007, eram originários das províncias da Zambézia (38,7\% e 46,1\% dos imigrantes em 1997 e 2007, respectivamente), Tete (20\% e 18,4\%), Inhambane $(18,9 \%$ e $12,2 \%$ ) e Manica $(12,4 \%$ e 13,9\%). Portanto, a maior imigração em Sofala provém da província da Zambézia (Mapas 10 e 11). 
Mapa 10: Fluxos migratórios internos de toda a vida - Sofala, 1997

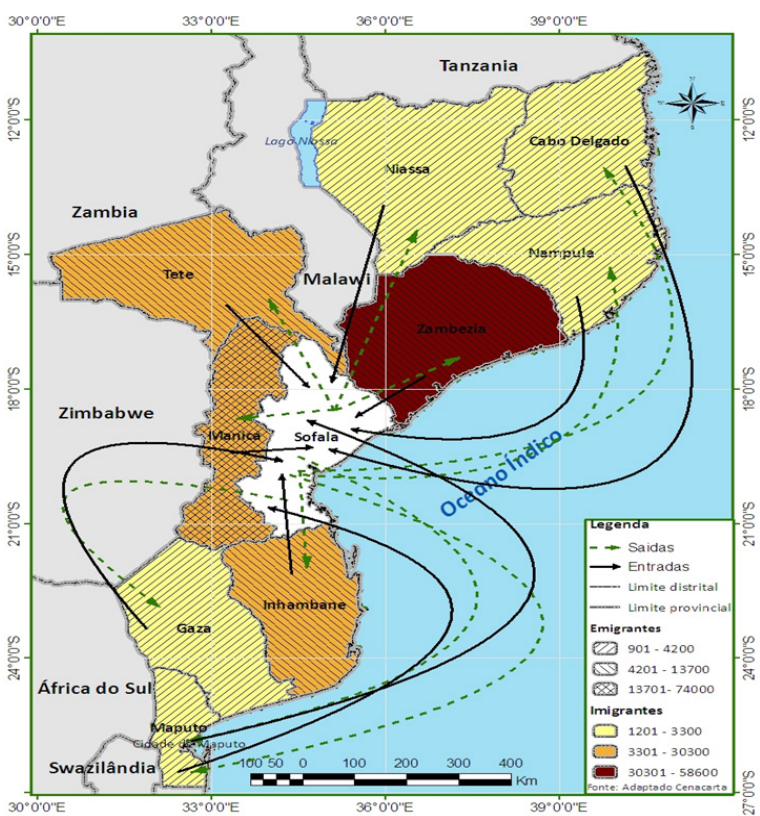

Fonte: INE (1999)

Mapa 11: Fluxos migratórios internos de toda a vida - Sofala, 2007

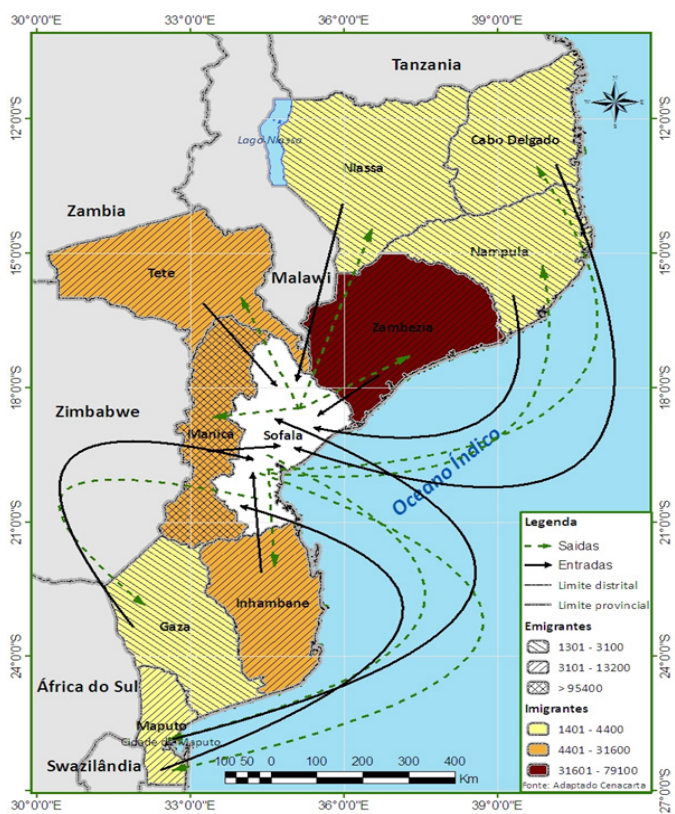

Fonte: INE (2010) 


\section{Província de Manica}

Manica é, também, uma das províncias localizadas na região central de Moçambique. Ela ocupa uma superfície de $62.272 \mathrm{Km}^{2}$ com uma população de 974.208 e 1.412.248 habitantes em 1997 e 2007, respectivamente. A província de Manica faz fronteira com a República do Zimbabwe, facto que contribui para a ocorrência da migração tanto internacional - migração laboral para as plantações de chá (Das Neves, 1998) - quanto interna, para as províncias limítrofes de Sofala, Tete e Inhambane (vide Mapas 12 e 13). De acordo com o Mapa 12, em 1997, os imigrantes acumulados de toda vida de Manica eram maioritariamente das províncias de Sofala (58,6\%), Tete $(18,8 \%)$ e Zambézia (8,9\%). Em 2007, os imigrantes acumulados de toda vida em Manica continuaram a ser maioritariamente de Sofala $(60,5 \%)$, Tete $(17,9 \%)$ e Zambézia (10,2\%) (Mapa 13).

Mapa 12: Fluxos migratórios internos de toda a vida - Manica, 1997

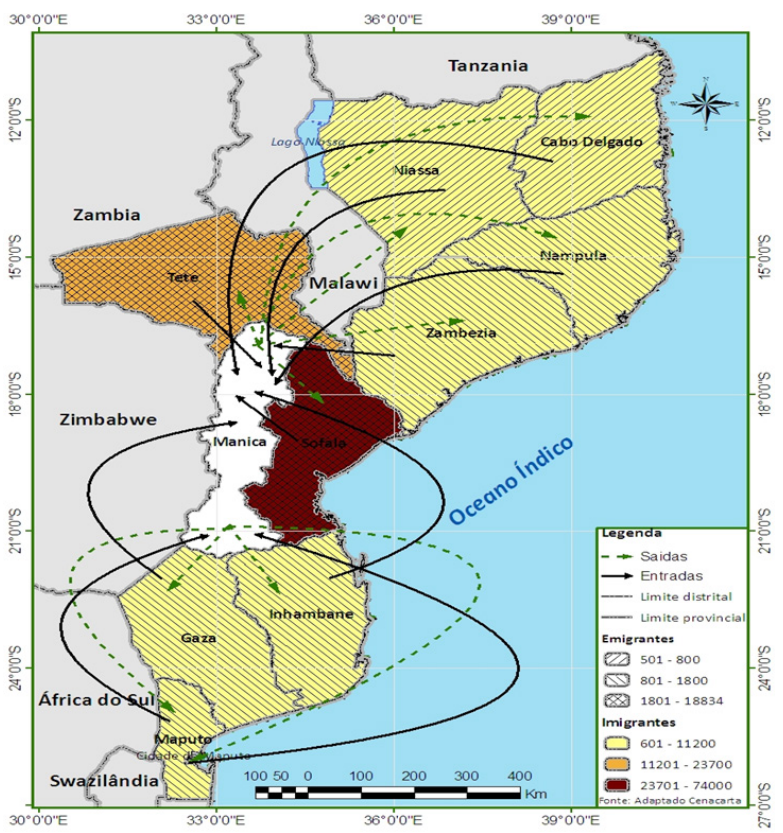

Fonte: INE (1999) 


\section{Mapa 13: Fluxos migratórios internos de toda a vida - Manica, 2007}

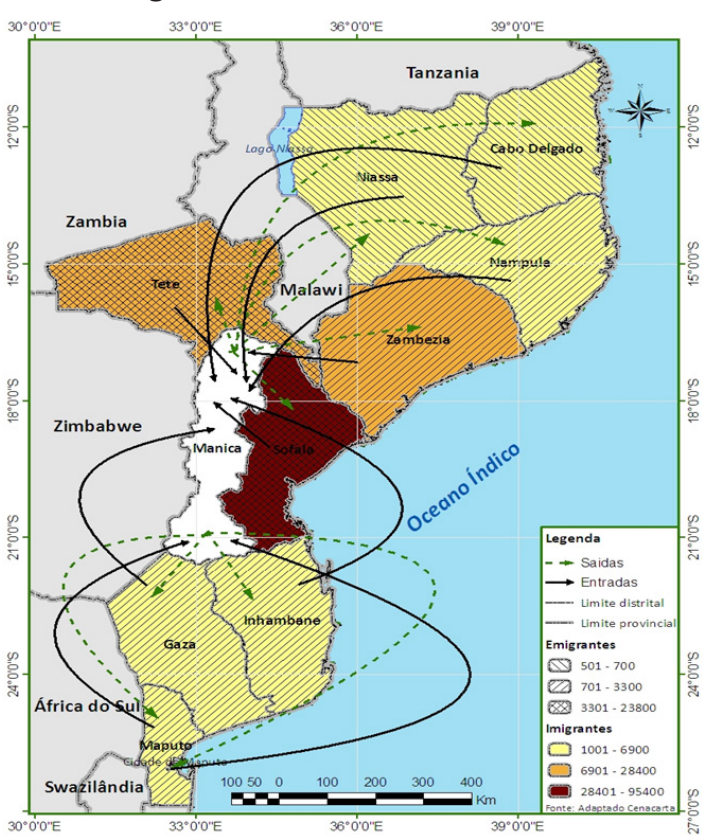

Fonte: INE (2010)

\section{Província da Zambézia}

A província da Zambézia situa-se na região central de Moçambique e possui uma área de 103.477 Km². Em 1997 tinha 2.891.809 habitantes, tendo passado para 3.849.455 habitantes em 2007. Como deve ter sido observado nos parágrafos anteriores, Zambézia é a província que apresenta mais emigrantes na região centro e com uma representatividade muito alta nas províncias do sul, em comparação com as restantes províncias do centro e norte. Entretanto, as razões para esta situação continuam não muito claras. Os índices de pobreza resultantes do Inquérito aos Agregados Familiares (IAF) e do Inquérito sobre Orçamento Familiar indicam que esta província está melhor posicionada em relação as outras da mesma região e do norte do país. Por exemplo, o MEF (2015) revelou que o IAF de 96 indicava que o índice de pobreza na Zambézia era de 67,6\%, contra 81,9\% em Tete e 71,9\% em Niassa. Ainda, IOF de 2002 indicou um índice de pobreza de 49,7\% na Zambézia, contra 60,5\% em Tete e 48,3\% em Niassa.

Quanto aos principais destinos dos emigrantes internos acumulados de toda da Zambézia, em 1997, o destaque, pela ordem de importância, vai para as províncias de Sofala (38\%), Nampula $(23,6 \%)$, Cidade de Maputo $(13,4 \%)$ e Manica (7,3\%) (vide Mapa 14). Em 2007, os destinos preferenciais 
continuaram a ser, pela ordem de importância, as províncias de Sofala (com $37,4 \%$ dos emigrantes), Nampula (19,2\%) e Cidade de Maputo (14,2\%); depois seguiram-se as províncias de Maputo (10\%), Manica $(7,6 \%)$ e Niassa $(5,7 \%)$ (Mapa 15). Portanto, cerca de $1 / 4$ dos emigrantes acumulados da Zambézia em 2007 encontravam-se na região sul de Moçambique.

\section{Mapa 14: Fluxos migratórios internos de toda a vida - Zambézia, 1997}

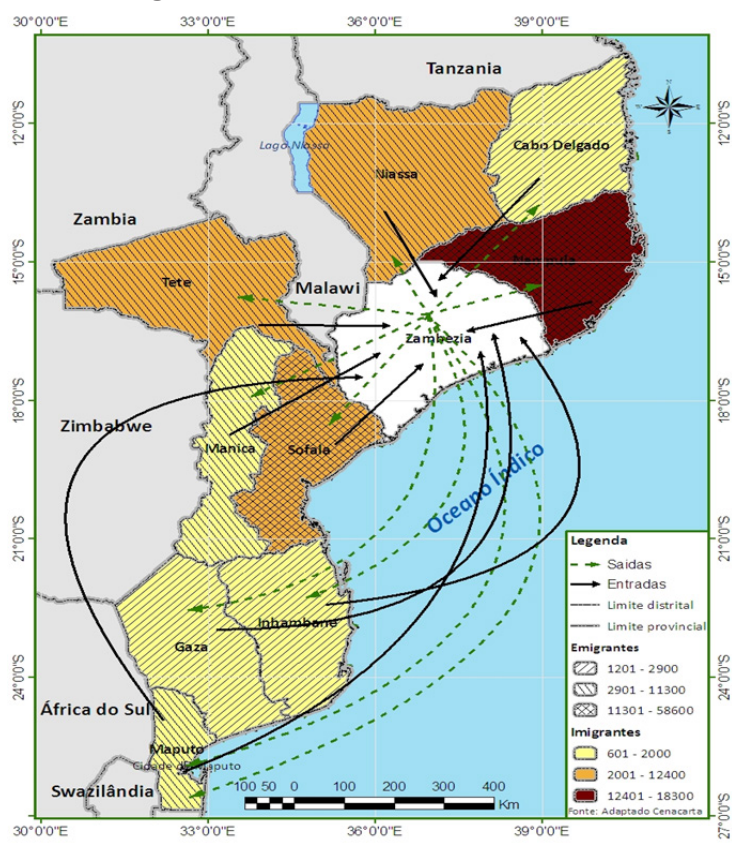

Fonte: INE (1999) 


\section{Mapa 15: Fluxos migratórios internos de toda a vida - Zambézia, 2007}

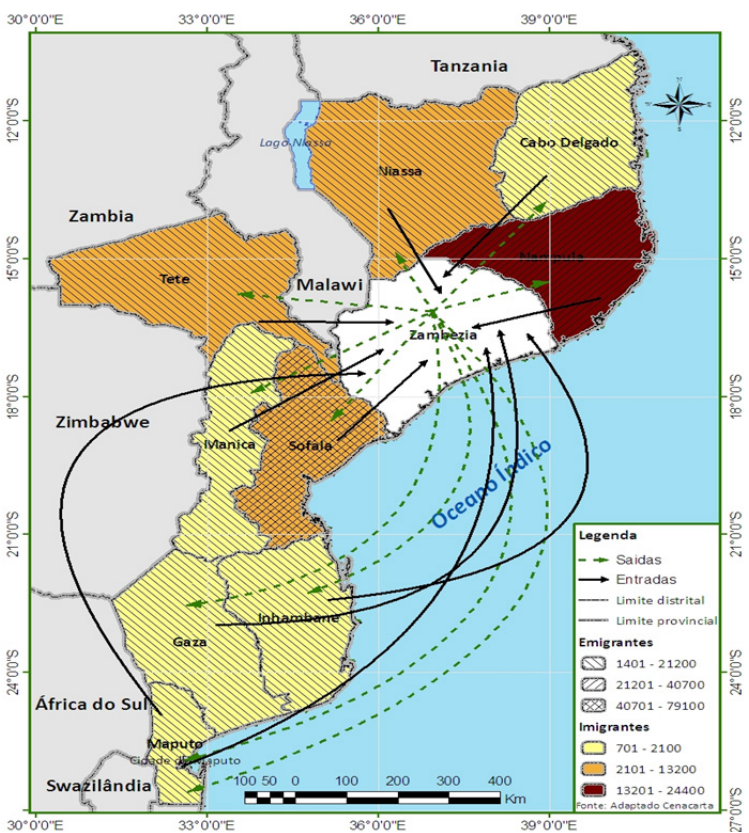

Fonte: INE (2010)

\section{Província de Tete}

A província de Tete, a mais ocidental da República de Moçambique, tem uma superfície de $98.416 \mathrm{Km}^{2}$. A sua população era de 1.144.604 habitantes em 1997, tendo passado para 1.783.967 habitantes em 2007. Tratando-se de uma província de emigração, segundo os censos demográficos de 1997 e 2007, a maioria dos seus emigrantes acumulados, em 1997, residia nas províncias de Sofala (39,6\%), Manica (31,1\%), Zambézia (12,2\%) e Cidade de Maputo (5,8\%) (Mapa 16). Igualmente, em 2007, a maioria dos emigrantes de toda a vida de Tete distribuía-se pelas províncias de Sofala (36,2\% dos emigrantes), Manica (32,5\%), Zambézia (12,8\%) e Cidade de Maputo (5,9\%) (Mapa 17). 
Mapa 16: Fluxos migratórios internos de toda a vida - Tete, 1997

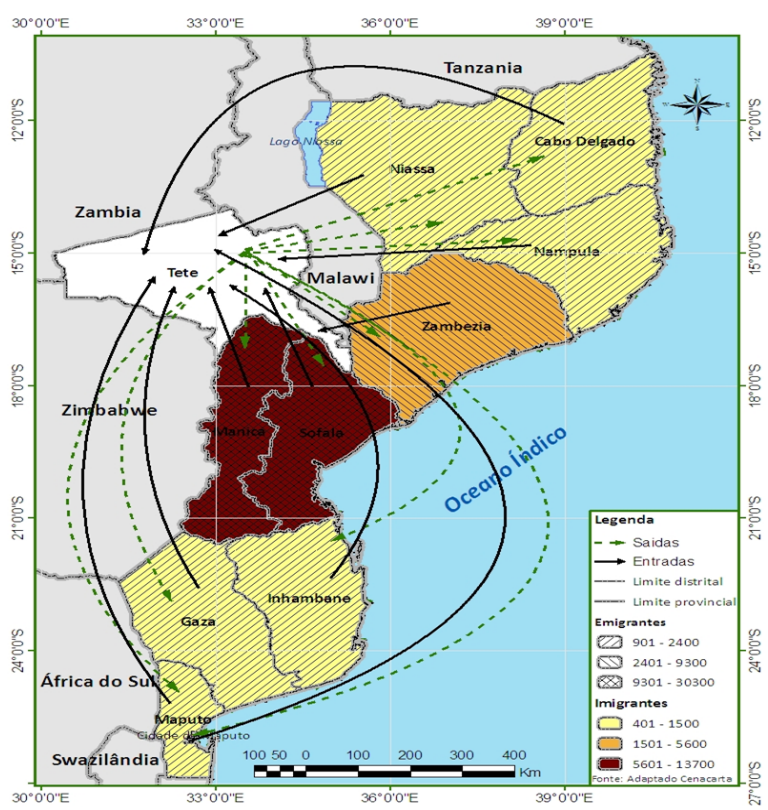

Fonte: INE (1999)

Mapa 17: Fluxos migratórios internos de toda a vida - Tete, 2007

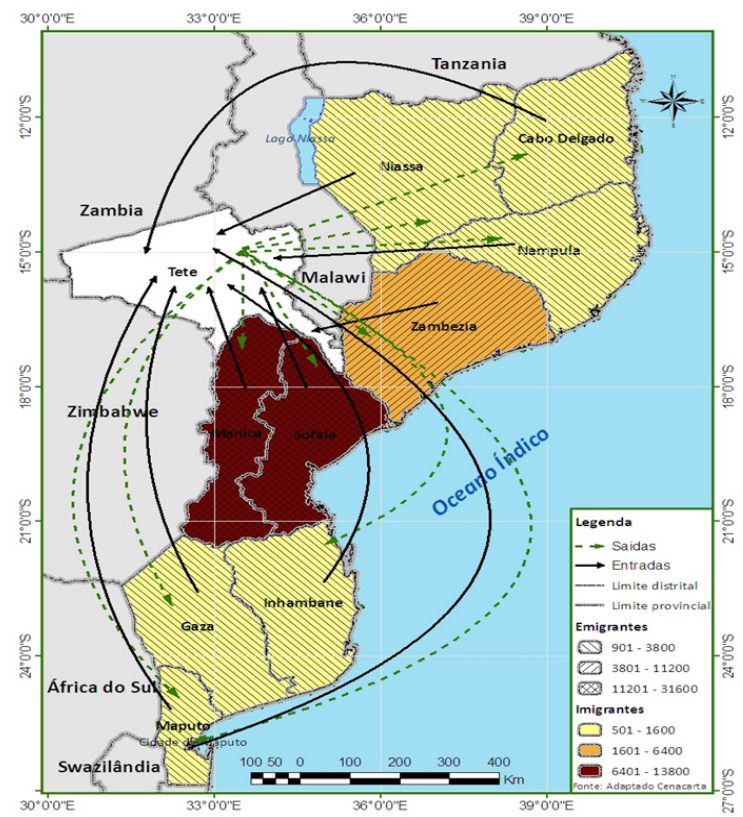

Fonte: INE (2010) 


\section{Província de Nampula}

A província de Nampula, localizada na região norte de Moçambique e ocupando uma superfície total de 81862 km², tinha, em 1997, 2.975.747 habitantes, tendo passado para 3.985.613 habitantes, em 2007. Segundo o censo demográfico de 1997, Nampula foi também uma das províncias de imigração acumulada, embora em menor escala. A maioria dos seus imigrantes de toda a vida era proveniente da província da Zambézia (43\%), seguida pelas províncias de Cabo Delgado (29,3\%) e Niassa (13,2\%) (Mapa 18). Todas estas províncias fazem fronteira com Nampula. Portanto, a sua proximidade geográfica da chamada "Capital Norte", a capital provincial de Nampula, pode ser em parte uma das causas explicativas desta imigração interna em Nampula.

\section{Mapa 18: Fluxos migratórios internos de toda a vida - Nampula, 1997}

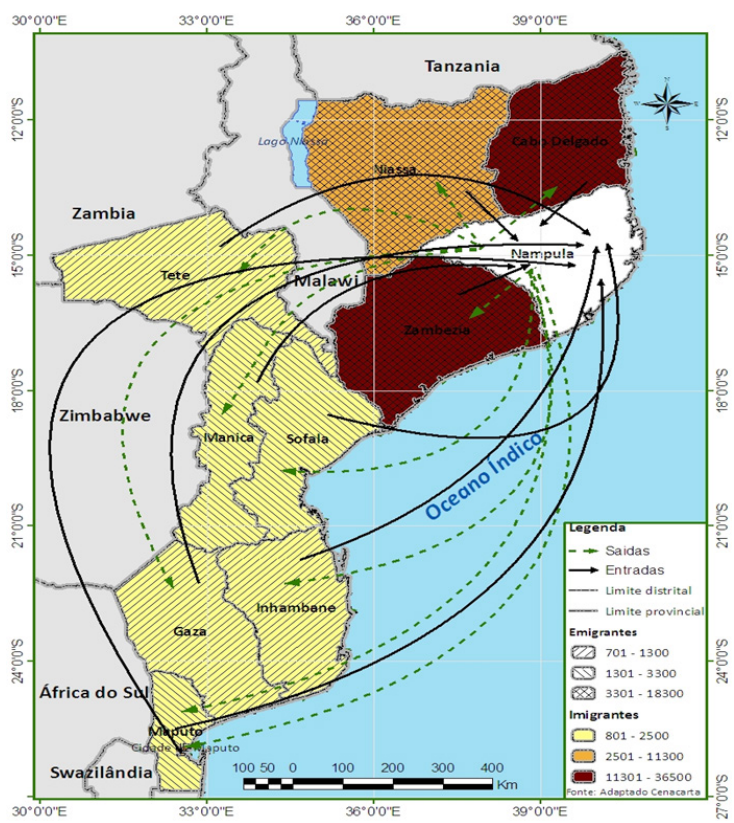

Fonte: INE (1999)

Entretanto, em 2007, Nampula passou a ser uma província de emigração acumulada. A maior parte dos emigrantes de toda a vida de Nampula, em 2007, distribuía-se pelas províncias de Cabo Delgado (26,1\% dos emigrantes), Zambézia $(24,6 \%)$ e Niassa $(21,6 \%)$ (Mapa 19). 


\section{Mapa 19: Fluxos migratórios internos de toda a vida - Nampula, 2007}

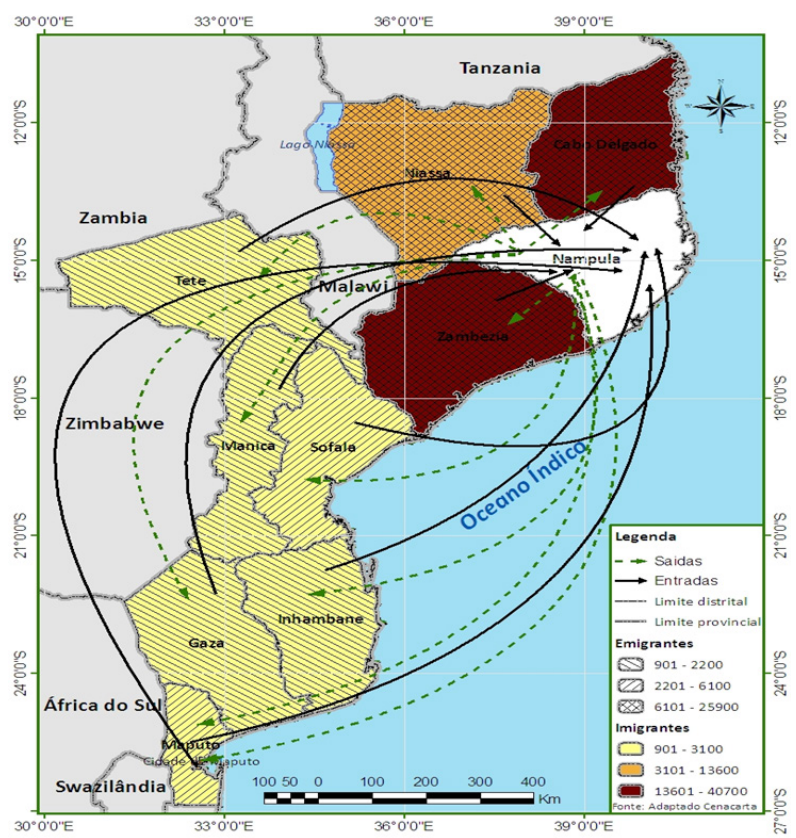

Fonte: INE (2010)

\section{Província do Niassa}

Niassa é a província mais extensa de Moçambique, com uma superfície de $122.826 \mathrm{Km}^{2}$, e a menos populosa. Em 1997 e 2007, a província do Niassa possuía uma população de 756.287 e 1.170 .783 habitantes, respectivamente. Niassa faz fronteira com a República do Malawi e a República Unida da Tanzânia. Historicamente, a migração na província do Niassa, segundo Raimundo (2010), ocorre entre as províncias de Nampula e Cabo Delgado e as Repúblicas do Malawi e Tanzânia. Segundo os censos demográficos de 1997 e 2007, a província do Niassa foi de imigração acumulada. O Mapa 20 indica que, em 1997, os imigrantes de toda a vida de Niassa eram maioritariamente de Nampula (46\%), Zambézia (26,6\%) e Cabo Delgado (8,7\%). Em 2007, os migrantes acumulados na província do Niassa continuaram ser provenientes maioritariamente das províncias vizinhas de Nampula $(46,9 \%)$ e Zambézia (26,4\%), conforme o Mapa 21. 


\section{Mapa 20: Fluxos migratórios internos de toda a vida - Niassa, 1997}

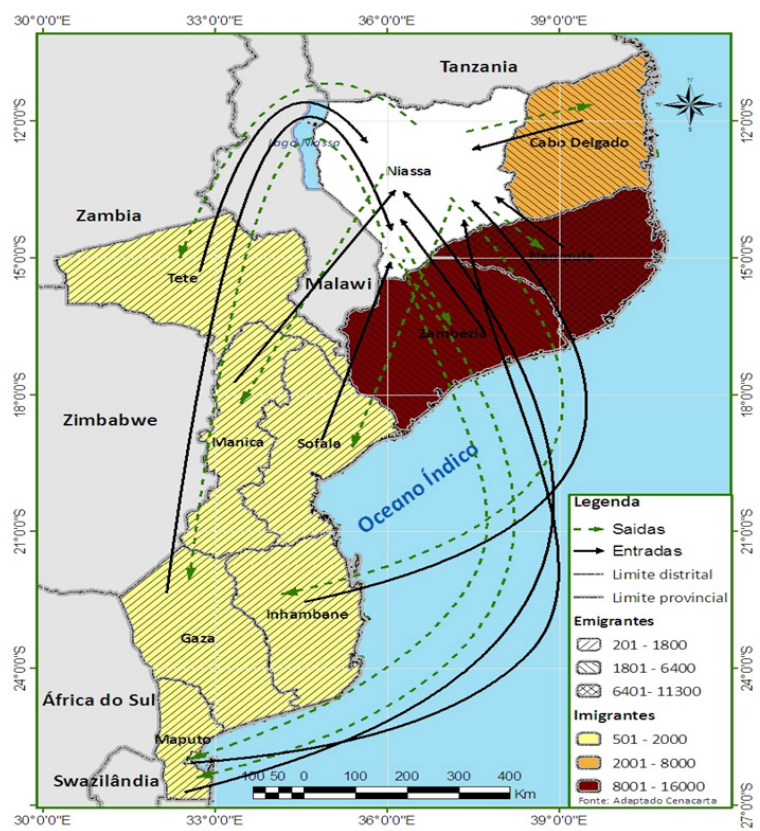

Fonte: INE (1999)

\section{Mapa 21: Fluxos migratórios internos de toda a vida - Niassa, 2007}

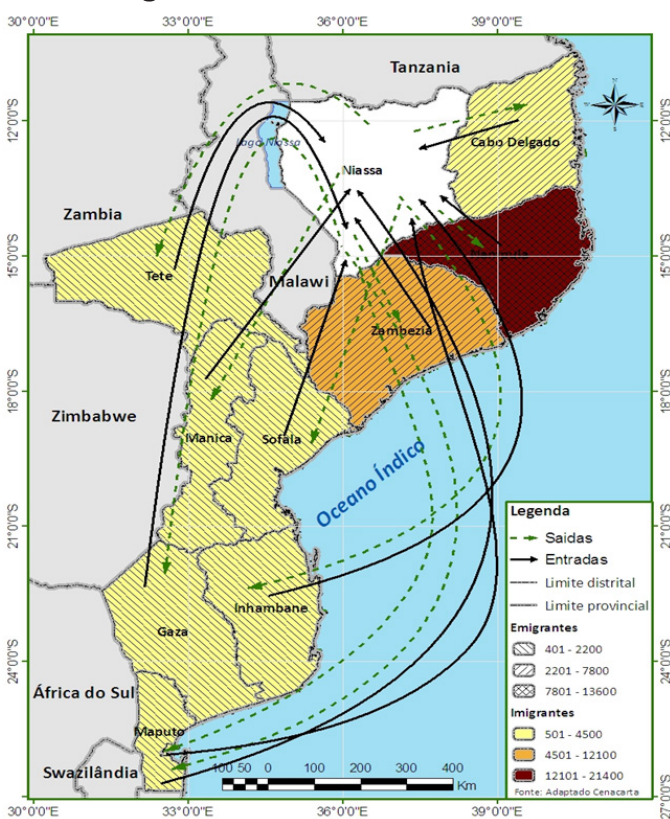

Fonte: INE (2010) 


\section{Cabo Delgado}

Com uma extensão de $78.777 \mathrm{~km}^{2}$, a província de Cabo Delgado localiza-se na região norte de Moçambique e faz fronteira com a República Unida da Tanzânia e com as províncias do Niassa e de Nampula. A sua população era de 1.287.814 habitantes em 1997, tendo passado para 1.606.568 habitantes em 2007. Os censos demográficos de 1997 e 2007 indicam que a província de Cabo Delgado foi de emigração. Em 1997, os emigrantes desta província encontravam-se distribuídos pelas províncias de Nampula (58,7\%), Cidade de Maputo cidade (11,5\%), Niassa (6,8\%), Maputo $(5,4 \%)$, Sofala $(4,8 \%)$ e Zambézia (4,6\%) (Mapa 22). Igualmente, em 2007, as províncias de destino dos emigrantes de Cabo Delgado continuaram a ser as mesmas, as províncias de Nampula $(57,4 \%)$, Cidade de Maputo $(11,1 \%)$, Niassa $(9,2 \%)$ e Maputo $(7,2 \%)$ (Mapa 23$)$.

\section{Mapa 22: Fluxos migratórios internos de toda a vida - Cabo Delgado, 1997}

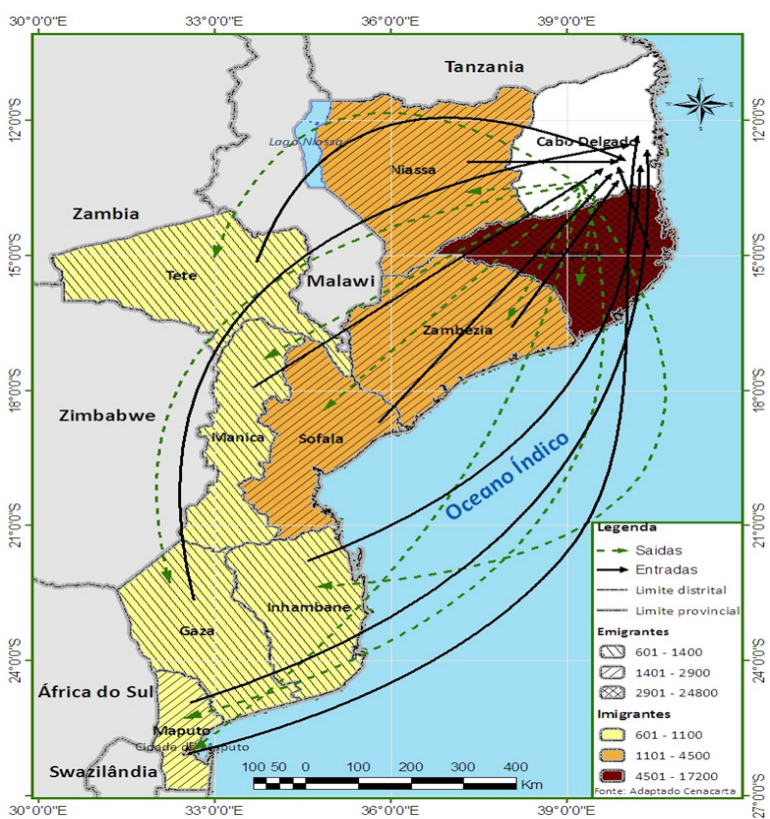

Fonte: INE (1999) 


\section{Mapa 23: Fluxos migratórios internos de toda a vida - Cabo Delgado, 2007}

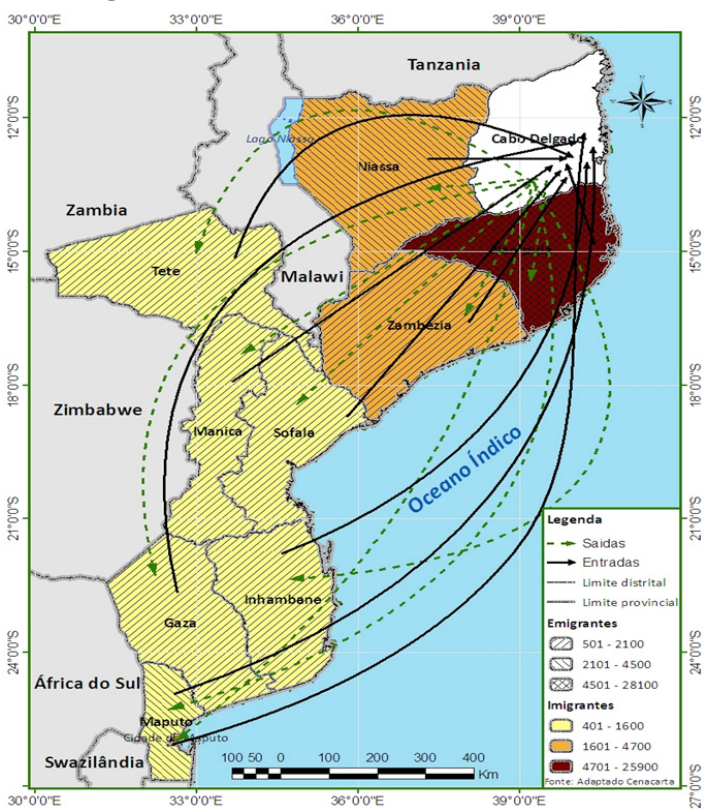

Fonte: INE (2010)

\subsection{Migração interprovincial de toda a vida por sexo em 1997 e 2007}

\section{Volumes da migração de toda a vida por sexo}

Os dados da migração interprovincial acumulada por sexo, para 1997 e 2007 indicam que, em 1997, a migração interna acumulada envolveu um total de 1.274.830 pessoas, das quais 614.878, ou seja 48\%, eram mulheres (Quadro 1). Para 2007, os dados indicam que, de um total de 1.549.101 migrantes internos acumulados de todas as províncias, as mulheres representavam 49,1\% do volume total da migração (Quadro 2).

\section{Quadro 1: Migração interna de toda a vida por sexo e província - Moçambique, 1997}

\begin{tabular}{l|cccccc}
\hline \multirow{2}{*}{ Província } & \multicolumn{2}{|c}{$\begin{array}{c}\text { Imigrantes internos } \\
\text { absolutos }\end{array}$} & \multicolumn{2}{c}{$\begin{array}{c}\text { Emigrantes internos } \\
\text { absolutos }\end{array}$} & \multicolumn{2}{c}{$\begin{array}{c}\text { Migração líquida aboluta } \\
\text { (ou saldo migratório) }\end{array}$} \\
\cline { 2 - 7 } & Homens & Mulheres & Homens & Mulheres & Homens & Mulheres \\
\hline Niassa & 20.811 & 12.249 & 18.115 & 13.280 & +2.696 & -1.031 \\
\hline $\begin{array}{l}\text { Cabo } \\
\text { Delgado }\end{array}$ & 18.208 & 12.932 & 25.368 & 16.862 & -7.160 & -3.930 \\
\hline Nampula & 48.685 & 35.997 & 42.174 & 27.784 & +6.511 & +8.213 \\
\hline Zambézia & 28.054 & 26.447 & 100.479 & 53.812 & -7.2425 & -2.7365 \\
\hline
\end{tabular}




\begin{tabular}{l|cccccc}
\hline Tete & 19.514 & 17.721 & 39.266 & 37.054 & -19.752 & -19.333 \\
\hline Manica & 65.176 & 61.041 & 21.306 & 20.589 & +43.870 & +40.452 \\
\hline Sofala & 83.204 & 68.178 & 63.779 & 62.997 & +19.425 & +5.181 \\
\hline Inhambane & 29.117 & 37.197 & 129.260 & 113.140 & -100.143 & -75.943 \\
\hline Gaza & 30.846 & 34.866 & 108.433 & 131.241 & -77.587 & -96.375 \\
\hline Maputo & 133.604 & 130.125 & 38.436 & 54.876 & +95.168 & +75.249 \\
\hline $\begin{array}{l}\text { Maputo } \\
\text { Cidade }\end{array}$ & 182.733 & 178.125 & 73.336 & 83.243 & +109.397 & +94.882 \\
\hline TOTAL & $\mathbf{6 5 9 . 9 5 2}$ & $\mathbf{6 1 4 . 8 7 8}$ & $\mathbf{6 5 9 . 9 5 2}$ & $\mathbf{6 1 4 . 8 7 8}$ & $\mathbf{0}$ & $\mathbf{0}$ \\
\hline
\end{tabular}

Fonte: INE (1999)

\section{Quadro 2: Migração interna de toda a vida por sexo e província - Moçambique, 2007}

\begin{tabular}{|c|c|c|c|c|c|c|}
\hline \multirow[t]{2}{*}{ Província } & \multicolumn{2}{|c|}{$\begin{array}{l}\text { Imigrantes internos } \\
\text { absolutos }\end{array}$} & \multicolumn{2}{|c|}{$\begin{array}{l}\text { Emigrantes internos } \\
\text { absolutos }\end{array}$} & \multicolumn{2}{|c|}{$\begin{array}{l}\text { Migração líquida aboluta } \\
\text { (ou saldo migratório) }\end{array}$} \\
\hline & Homens & Mulheres & Homens & Mulheres & Homens & Mulheres \\
\hline Niassa & 27.387 & 18.093 & 20.312 & 15.650 & +7.075 & +2.443 \\
\hline $\begin{array}{l}\text { Cabo } \\
\text { Delgado }\end{array}$ & 24.957 & 15.990 & 28.154 & 20.637 & -3.197 & -4.647 \\
\hline Nampula & 54.596 & 42.978 & 59.735 & 39.147 & -5.139 & +3.831 \\
\hline Zambézia & 35.119 & 31.884 & 132.277 & 79.185 & -97.158 & -47.301 \\
\hline Tete & 22.130 & 19.159 & 44.483 & 42.537 & -22.353 & -23.378 \\
\hline Manica & 80.021 & 77.648 & 27.010 & 26.509 & +53.011 & +51.139 \\
\hline Sofala & 92.470 & 78.828 & 81.400 & 78.990 & +11.070 & -162 \\
\hline Inhambane & 29.250 & 37.876 & 138.892 & 133.914 & -109.642 & -96.038 \\
\hline Gaza & 29.965 & 33.484 & 108.413 & 143.247 & -78.448 & -109.763 \\
\hline Maputo & 223.936 & 229.411 & 35.028 & 50.473 & +188.908 & +178.938 \\
\hline $\begin{array}{l}\text { Maputo } \\
\text { Cidade }\end{array}$ & 168.948 & 174.971 & 113.075 & 130.033 & +55.873 & +44.938 \\
\hline TOTAL & 788.779 & 760.322 & 788.779 & 760.322 & 0 & 0 \\
\hline
\end{tabular}

Fonte: INE (2010)

\subsection{Migração interprovincial do período 2002-2007}

A análise da migração do período 2002-2007 é feita com base nos dados do censo demográfico de 2007. O volume total da migração interprovincial em Moçambique, no período 2002-2007, foi de 417.427 pessoas (Quadro 3). 


\section{Quadro 3: Migração interprovincial do período 2002-2007 - Moçambique, 2007}

\begin{tabular}{l|ccc}
\hline \multicolumn{1}{c|}{ Província } & $\begin{array}{c}\text { Imigrantes internos } \\
\text { absolutos }\end{array}$ & $\begin{array}{c}\text { Emigrantes } \\
\text { internos absolutos }\end{array}$ & $\begin{array}{c}\text { Migração líquida } \\
\text { absoluta (ou saldo } \\
\text { migratório) }\end{array}$ \\
\hline Niassa & 12.854 & 12.806 & +48 \\
\hline Cabo Delgado & 16.604 & 12.250 & +4.354 \\
\hline Nampula & 28.703 & 33.365 & -4.662 \\
\hline Zambézia & 32.295 & 47.260 & -14.965 \\
\hline Tete & 10.009 & 19.130 & -9.121 \\
\hline Manica & 32.296 & 18.003 & -4.986 \\
\hline Sofala & 39.154 & 44.140 & -12.338 \\
\hline Inhambane & 33.463 & 45.801 & -11.060 \\
\hline Gaza & 23.250 & 34.310 & +102.002 \\
\hline Maputo & 128.359 & 26.357 & -63.565 \\
\hline Maputo Cidade & 60.440 & 124.005 & 0 \\
\hline TOTAL & 417.427 & 417.427 & \\
\hline
\end{tabular}

Fonte: INE (2010)

Durante o período 2002-2007, apenas quatro províncias (Maputo, Manica, Cabo Delgado e Niassa) tiveram um saldo migratório positivo. Neste conjunto, destaca-se, mais uma vez, a província de Maputo que continuou a liderar as províncias de imigração, com um ganho líquido de +102.002 pessoas (provenientes maioritariamente da Cidade de Maputo, Inhambane e Gaza). A seguir à província de Maputo estão as províncias de Manica e Cabo Delgado, com uma migração líquida de +14.293 e +4.354 pessoas, respectivamente. A província do Niassa foi a que teve o menor ganho líquido de apenas +48 pessoas.

De entre as províncias que tiveram uma migração líquida negativa, a Cidade de Maputo aparece na liderança, com uma perda líquida de -63.565 pessoas (principalmente a favor das províncias de Maputo, Inhambane e Gaza). A seguir à cidade de Maputo está a província da Zambézia, com uma migração líquida negativa de-14.965 pessoas. A menor perda líquida, de -4.662 pessoas, verificou-se na província de Nampula.

Note-se que, no quinquénio 2002-2007, a província de Maputo ganhou população proveniente maioritariamente da Cidade de Maputo, e das províncias de Inhambane e Gaza. Enquanto isso, a província de Manica ganhou população principalmente das províncias de Sofala, Tete e Zambézia; Cabo Delgado também ganhou população proveniente maioritariamente das províncias de Nampula, Niassa e Zambézia; e, finalmente, a provincia do 
Niassa teve ganhos de população das províncias de Nampula, Zambézia e Cabo Delgado.

\section{Conclusões}

As estimativas de migração interprovincial aqui apresentadas permitiram identificar as tendências de migração interna em Moçambique a este nível político-administrativo. De um modo geral, e do ponto de vista de sua dinâmica migratória, as províncias podem ser classificadas em três grupos. No primeiro grupo fazem parte as províncias de Niassa, Manica e Maputo que, em todos os períodos de referência, se apresentaram como províncias de imigração interna. O segundo grupo é composto pelas províncias de Zambézia, Tete, Inhambane e Gaza que, em todos os períodos analisados, revelaram-se como sendo províncias de emigração interna. Por último, no terceiro grupo estão as províncias que, de um período de referência para outro, mudaram de uma tendência migratória para outra. Concretamente, pode-se falar da província de Sofala que passou de uma tendência de província de imigração, na migração de toda a vida de 1997 e 2007, para a de emigração no período 2002-2007. No caso de Cabo Delgado, a mudança foi de uma tendência de província de emigração, na migração de toda a vida de 1997 e 2007, para a de província de imigração no período 2002-2007. Nampula passou de província de imigração, na migração de toda a vida de 1997, para província de emigração, na migração de toda a vida de 2007 e na do período 2002-2007. Finalmente, a Cidade de Maputo deixa de ser de imigração, na migração de toda a vida de 1997 e 2007, e passa a ser de emigração, no quinquénio 2002-2007.

Um aspecto particular da migração interna na região sul do país é o facto de ela envolver cada vez mais a população a feminina. Nesta região, a proporção de migrantes do sexo feminino no volume total de migrantes supera a dos migrantes do sexo masculino. Nas restantes regiões continua ainda a predominância da migração masculina.

O presente estudo não permite avançar explicações conclusivas sobre as causas das diferenças observadas entre as províncias, quanto às tendências migratórias. Contudo, pode-se fazer algumas inferências das possíveis causas em certas províncias. No caso das províncias de Manica e Maputo a tendência de imigração pode ser associada com as oportunidades que elas oferecem, quanto ao emprego, pelo facto de apresentarem empreendimentos económicos de grande impacto tanto a nível local quanto a nível nacional e internacional. A tendência de emigração nas províncias de Zambézia, Tete, Inhambane e Gaza pode estar associada com a tradição da população destas províncias para o trabalho migratório, feita por etapas, em particular para as minas da África do Sul (no caso de Inhambane e Gaza) e agroindústrias em Sofala (no caso de Zambézia e Tete). A tendência recente de emigração na Cidade de Maputo 
tem a ver, essencialmente, com o reflorescimento da cidade da Matola e dos novos bairros pertencentes à província de Maputo.

Estudos analíticos são necessários para o melhor entendimento das causas das tendências migratórias de cada uma das províncias, tendo-se em conta as particularidades de cada uma delas no contexto das políticas de desenvolvimento socioeconómico do país.

Finalmente, chama-se atenção para que se tenha em mente de que as tendências migratórias destacas neste texto referem-se a um período relativamente longínquo (há mais de 10 anos atrás). Provavelmente, estas tendências devem ter mudado nos dias de hoje, em conexão com a actual dinâmica das descobertas de recursos minerais e energéticos no território nacional, caracterizada pela emergência de novos pólos de desenvolvimento socioeconómico. A dissipação desta dúvida poderá ser feita com base na análise da informação do censo demográfico de 2017, a ser publicada brevemente.

\section{Referências bibliográficas}

COVANE, Luis Antonio. Migrant Labour and Agriculture in Southern Mozambique with Especial Reference to Lower Limpopo Valley, 1920-1992 (Dissertação de Doutoramento). London: Institute of Commonwealth Studies, University of London, 1996.

DAS NEVES, Joel Mauricio. Economy, Society and Labour Migration in Central Mozambique, 1930-c. 1965: A case Study of Manica Province (Dissertação de Doutoramento). London: School of Oriental and African Studies, University of London, 1998.

DE VLETTER, Fion. Labour migration in South Africa: the lifeblood for southern Mozambique. In: MacDONALD, David A. (ed.). On borders: Perspectives on International Migration in Southern Africa. Southern African Migration Project. New York: St Martin's Press, 2000, p. 46-70.

INE (Instituto Nacional de Estatística). III Recenseamento Geral da População e Habitação 2007: Resultados Definitivos - Moçambique. Maputo, 2010.

INE (Instituto Nacional de Estatística). II Recenseamento Geral da População e Habitação 1997: Resultados Definitivos - Moçambique. Maputo, 1999.

MEF (Ministério da Economia e Finanças). Pobreza e bem-estar em Moçambique: Quarta avaliação nacional - Inquérito ao Orçamento Familiar - IOF-2014/15. Maputo, 2015.

MINED. Atlas Geográfico. Volume I. Maputo, 1986.

MUANAMOHA, Ramos Cardoso. Dynamics of undocumented Mozambican labour migration to South Africa. Germany: Verlag Dr. Muller Aktiengesellschaft \& Co. KG, 2010.

PENVENNE, Jeanne. A History of African Labor in Lourenço Marques, Mozambique, 1877 to 1950 (Dissertação de Doutoramento). Boston, 1982. 
PILILÃO, Fernando. Moçambique: evolução da toponímia e da divisão territorial 1974-1987. Maputo: Ministério da Administração Estatal e Instituto de Planeamento Físico, 1989.

RAIMUNDO, Inês M. Gender, Choice and Migration: Household Dynamics and Urbanisation in Mozambique. Germany: Verlag Dr. Muller Aktiengesellschaft \& Co. KG, 2010.

RAIMUNDO, Inês M. International Migration Management and Development in Mozambique: What Strategies? International Migration, v. 4, n. 3, p. 1-30, 2009. RAIMUNDO, Inês M.; MUANAMOHA, Ramos Cardoso. A dinâmica migratória em Moçambique. In: ARNALDO, Carlos; CAU, Boaventura Manuel (orgs.). Dinâmicas da População e Saúde em Moçambique. Maputo: CEPSA, 2013, p. 157-182.

RAIMUNDO, Inês M.; RAIMUNDO, José A. O impacto do discurso das "descobertas" dos recursos minerais no despovoamento rural de Moçambique. Revista de estudos ibéricos IBEROGRAFIAS, Ano XVIII, n. 13, p. 137-152, 2017. REPÚBLICA DE MOÇAMBIQUE. Constituição da República. Boletim da República, I Série, Número 51, Quarta-feira, 22 de Dezembro de 2004. Maputo, 2004.

SAIDE, Alda S.; PITROSSE, Filipe. O trabalho migratório de moçambicanos nas farmas da África do Sul, 1975-presente. In: CAP (ed.). Reassentamento Populacional, Governação Autárquica, Trabalho Migratório e Relações Internacionais entre Moçambique e Malawi. Maputo: PubliFix, 2012, p. 123- 177.

SITÓI, Rogério. Migrantes internos da província da Zambézia: o Caso do Mercado Estrela Vermelha, Cidade de Maputo (Trabalho de Licenciatura não publicado). Maputo: Faculdade de Letras e Ciências Sociais da Universidade Eduardo Mondlane, 2000.

Recebido para publicação em 31.08.2018

Aceito para publicação em 01.11.2018

Received for publication in August 315t, 2018 Accepted for publication in November 015t, 2018

ISSN impresso 1980-8585

ISSN eletrônico 2237-9843

http://dx.doi.org/10.1590/1980-85852503880005403 